\title{
O Projeto de Educação de Jovens e Adultos de Assentamentos de Reforma Agrária do Piauí (Proejapi) no contexto do Pronera
}

Jullyane Frazão Santana ${ }^{1}$, (iD) Rosana Evangelista da Cruz², (iD) Marli Clementino Gonçalves ${ }^{3}$

${ }^{1}$ Universidade de São Paulo - USP. Programa de Pós Graduação em Educação. Campus de Ribeirão Preto.Avenida Bandeirantes, 3900, Monte Alegre. Ribeirão Preto - SP. Brasil. ${ }^{2,3}$ Universidade Federal do Piauí - UFPI.

Autor para correspondência/Author for correspondence: jullyanefrazao@hotmail.com

RESUMO. O Programa Nacional de Educação da Reforma Agrária avançou em relação às políticas desenvolvidas historicamente no Brasil para a educação das populações campesinas, representando uma mudança de paradigma. Este artigo foi direcionado pelo seguinte problema de pesquisa: como se materializou a implantação do Pronera no estado do Piauí, mediante o Projeto de Educação de Jovens e Adultos de Assentamentos de Reforma Agrária (Proejapi)? O objetivo foi analisar o processo de implantação do Pronera/Proejapi no Estado. A investigação foi baseada na revisão da literatura, análise documental e entrevistas com diferentes sujeitos das instituições e movimentos imbricados com o processo de implantação do Programa. Os resultados indicaram que esse processo envolveu dificuldades relacionadas à precariedade estrutural dos assentamentos; ao nível de formação dos monitores; aos aspectos burocráticos de tramitação do processo; à descontinuidade na liberação das parcelas acordadas nos planos de trabalho e ao atraso das atividades pedagógicas, elementos que interferiram na dinâmica de execução do Projeto. Os problemas enfrentados foram sendo superados pelo engajamento da equipe pedagógica e dos movimentos sociais e sindicais envolvidos, revelando que o Pronera/Proejapi teve papel central na ampliação dos processos de escolarização e formação de pessoas engajadas nas lutas pelo direito à educação e pela transformação social.

Palavras-chave: educação do campo, pronera/proejapi, política educacional, educação de jovens e adultos. 


\title{
The Project for Youth and Adults Education in Agrarian Reform Settlements in Piauí state (Proejapi) in the context of Pronera
}

\begin{abstract}
The National Agrarian Reform Education Program has advanced in relation to the policies historically developed in Brazil for the education of countryside populations, representing a paradigm shift. This article was directed by the following research problem: how did the implementation of Pronera materialize in the State of Piauí, through the Youth and Adult Education Project of Agrarian Reform Settlements? The objective is to analyze the Pronera implantation process in the State. The investigation was based on literature review, document analysis and interviews with different subjects from the institutions and movements involved in the implementing process of the Program. The results indicate that this process involved difficulties related to the structural precariousness of the settlements; the level of monitors training; the bureaucratic aspects of the process processing; the discontinuity in the release of the installments agreed in the work plans and the delay in pedagogical activities, elements that interfered in the dynamics of the Project's execution. The problems faced were being overcome by the engagement of the pedagogical team and the social and union movements involved, revealing that Pronera played a central role in expanding the processes of schooling and training of the people engaged in the struggles for the right to education and social transformation.
\end{abstract}

Keywords: rural education (countryside), pronera/proejapi, educational policy, youth and adult education. 


\section{El Proyecto de Educación para Jóvenes y Adultos en Asentamientos de Reforma Agraria en Piaú (PROEJAPI) en el contexto de PRONERA}

RESUMEN. El Programa Nacional de Educação para a Reforma Agraria ha avanzado en relación con las políticas históricamente desarrolladas en Brasil para la educación de las poblaciones campesinas, lo que representa un cambio de paradigma. Este artículo fue dirigido por el siguiente problema de investigación: ¿cómo se materializó la implementación de Pronera en el Estado de Piauí, a través del Proyecto de Educación de Jóvenes y Adultos de los Asentamientos de Reforma Agraria? El objetivo es analizar el proceso de implantación de Pronera en el Estado. La investigación se basó en la revisión de literatura, análisis de documentos y entrevistas con diferentes sujetos de las instituciones y movimientos involucrados en el proceso de implementación del Programa. Los resultados indican que este proceso implicó dificultades relacionadas con la precariedad estructural de los asentamientos; el nivel de entrenamiento de los monitores; los aspectos burocráticos del procesamiento del proceso; la discontinuidad en el lanzamiento de las cuotas acordadas en los planes de trabajo y el retraso en las actividades pedagógicas, elementos que interfirieron en la dinámica de la ejecución del Proyecto. Los problemas enfrentados fueron superados por la participación del equipo pedagógico y los movimientos sociales y sindicales involucrados, revelando que Pronera desempeñó un papel central en la expansión de los procesos de escolarización y capacitación de las personas involucradas en las luchas por el derecho a la educación y la transformación de la sociedad.

Palabras clave: educación rural, pronera/proejapi, política educativa, educación de jóvenes y adultos. 


\section{Introdução}

A construção e institucionalização de políticas públicas para a Educação do Campo no Brasil tem sua expressão fundacional no Programa Nacional de Educação para Reforma Agrária (Pronera), que, por sua vez, decorre da ação de sujeitos coletivos na elaboração de uma política pública, inscrita em um "contexto complexo de pressão das classes sociais e nos limites estruturais da economia" (Faleiros, 1986, p. 32). Esse Programa não se restringe a um projeto educacional, porque tem como horizonte a transformação social, estando vinculado às lutas do campo pela Reforma Agrária e pela emancipação e superação das relações de dominação e violência instituídas no meio rural brasileiro.

No Brasil, são "gritantes as diferenças entre o ensino que é propiciado às populações urbanas e o que é destinado às populações rurais" (Furtado, 2004, p. 89). Para Ferraro (2012), o interesse do Estado pela educação dos povos rurais tem uma estreita relação com o movimento de industrialização e urbanização do país, sendo o latifúndio um fator determinante para o analfabetismo no campo.

A partir dos anos de 1980, com a organização do Movimento de Trabalhadores Sem Terra (MST), a educação ofertada no meio rural ganhou novas perspectivas no âmbito da luta pela Reforma Agrária no Brasil, constituindo-se como uma das principais bandeiras do segmento, pois o direito a terra pressupõe o direito a uma vida digna, o que inclui o acesso à educação.

Nos anos de 1990, a negligência histórica do Estado para com a educação nacional ficou evidente, pois o número de analfabetos no país chegou à marca dos 48 milhões de brasileiros, com maior índice de concentração nos bolsões de pobreza urbano e no meio rural. Naquele momento, o descaso em relação ao atendimento da população foi intensificado pela ausência de garantias constitucionais que pautassem as especificidades dos povos do campo (Coutinho, 2009).

O Pronera, institucionalizado pelo Ministério Extraordinário de Política Fundiária (MEPF), por meio da Portaria n¹0/98, é resultado da reivindicação dos movimentos populares e sindicais - que levaram para a cidade a problemática histórica que penalizava a população rural - em defesa da escolarização de jovens e adultos residentes em áreas de assentamento e/ou acampamento, tendo como objetivo elevar a qualidade de vida no meio rural, por meio de uma educação desvinculada dos modelos urbanocêntricos e com vistas à sustentabilidade. 
A gestão do Programa é baseada em um modelo tripartite, com a participação dos movimentos sociais, das universidades e do governo federal. Os cursos são ofertados, em seu âmbito, nas seguintes modalidades e níveis: Educação de Jovens e adultos (EJA) - alfabetização e escolarização, anos iniciais e finais; EJA Médio, Nível Médio concomitante com o técnico profissionalizante e o técnico profissionalizante; Nível Superior; Especialização; Pós-graduação Stricto Sensu e Residência Agrária (curso de especialização); e concessão de bolsas de capacitação e formação profissional em assistência técnica, pedagógica e social (Incra, 2016).

Os cursos ofertados no âmbito do Pronera visam à formação de sujeitos críticos e reflexivos para atuar no meio rural brasileiro. Nesse sentido, compreendendo que o público alvo do Pronera é a "população jovem e adulta das famílias beneficiárias das Áreas de Reforma Agrária criadas ou reconhecidas pelo Incra e do Programa Nacional de Crédito Fundiário (PNCF)" (Incra, 2016), ou seja, trabalhadores rurais, destaca-se que, com exceção dos cursos de alfabetização e escolarização, anos iniciais e finais, os demais cursos supracitados funcionam em regime de alternância, permitindo a conciliação entre as atividades desenvolvidas no campo e a permanência dos educandos nos processos de educação formal.

Segundo o Instituto Nacional de Colonização e Reforma Agrária (Incra), entre os anos de 1998 a 2018, o Programa ofertou 499 cursos em parceria com 94 instituições de ensino, atendendo a 186.734 beneficiários em todas as modalidades de ensino, desde a educação de jovens e adultos até programas de pós-graduação (Incra, 2018). Assim, é importante a construção do conhecimento sobre essa política, sob a perspectiva de avaliar sua efetividade para os povos do campo.

As práticas educativas que se desenvolvem no âmbito do Pronera pretendem proporcionar o acesso à educação para os povos do campo, com o objetivo de reverter os altos índices de analfabetismo, a distorção idade-série e a evasão escolar, resultantes de uma multiplicidade de fatores de ordem estrutural, com ênfase nas dificuldades enfrentadas pelos jovens que migram do campo para a cidade intuindo acessar melhores condições de vida e níveis mais altos de escolarização.

No estado do Piauí, o processo de implantação do Pronera desdobrou-se entre os anos de 1998 a 2003, no âmbito do Projeto de Educação de Jovens e Adultos de Assentamentos de 
Reforma Agrária do Piauí (Proejapi). Nesse período, foram assinados três convênios entre o Incra e a Fundação de Desenvolvimento e Apoio à Pesquisa, Ensino e Extensão do Piauí (Fundape), resultantes da interlocução do Movimento dos Trabalhadores Sem Terra (MST) e da Federação dos Trabalhadores Rurais Agricultores e Agricultoras Familiares do Estado do Piauí (Fetag) com a Universidade Federal do Piauí (UFPI). Entre 1999 e 2002, foi executado um convênio de alfabetização de jovens e adultos e escolarização de monitores. E entre 2001 e 2003, outros dois convênios, um de alfabetização e um de escolarização nos anos iniciais do Ensino Fundamental.

Proejapi foi um nome definido pela equipe do Pronera no Piauí, configurandose como um dos únicos estados a dar um nome específico para o projeto de alfabetização e escolarização de Jovens e Adultos no contexto do Pronera. Considerando tal especificidade, no decorrer deste artigo será utilizada a nomenclatura Pronera/Proejapi para tratar do referido Projeto. No tocante aos convênios, destaca-se que, considerando a escassez de documentos que permitissem a efetivação da análise dos três convênios que compreendem a implantação do Pronera no Piauí, firmados entre 19992003, optou-se pela análise do Convênio
Incra/Pronera/UFPI - Alfabetização, tendo em vista que foi o único processo disponível na Superintendência do Incra, no Piauí.

O convênio supracitado foi celebrado no dia 30 de novembro de 2001, entre o Incra, na condição de concedente, a Fundape, como convenente, e a UFPI, como interveniente, com o objetivo de formar "50 turmas de alfabetização de jovens e adultos trabalhadores rurais, totalizando 1.000 alfabetizandos, em projetos de assentamento do INCRA no estado do Piauí" (Incra, 2003). Para a elaboração e execução dessa proposta, o curso contou com a participação do MST/PI e da Fetag/PI. O Pronera/Proejapi - Alfabetização situa-se, historicamente, entre os últimos anos do governo de Fernando Henrique Cardoso (FHC) (2002) e o primeiro ano do de Luís Inácio Lula da Silva (2003), por conta das prorrogações de vigência do convênio, que, por sua vez, deveria ter sido concluído no ano de 2002.

O convênio foi assinado e executado em um contexto no qual o Pronera, em nível nacional, não tinha uma rubrica orçamentária, sendo necessárias sucessivas mobilizações para garantir o financiamento de suas ações (Molina, 2003). Não obstante, destacam-se os contingenciamentos anuais e a descontinuidade nas liberações que 
deveriam fazer frente à execução dessas ações, ameaçando tanto a abertura de novos convênios quanto a continuidade dos cursos (Marialva, 2011).

O presente artigo é direcionado pelo seguinte problema de pesquisa: considerando o Pronera como um Programa que avançou em relação às políticas para a educação do campo desenvolvidas historicamente no Brasil, como se materializou a sua implantação no estado do Piauí, mediante o Projeto de Educação de Jovens e Adultos de Assentamentos de Reforma Agrária do Piauí (Proejapi)?

A relevância do estudo centrou-se na necessidade de assegurar o registro da história da política para a Educação do Campo, especialmente no contexto em que se vivencia, de forma acelerada, o desmonte das políticas no setor. Esse desmonte é decorrente da frágil institucionalização do Pronera, que não foi assegurada como política de Estado, criando possibilidade de ataques às propostas inclusivas semeadas no campo da educação popular. Ademais, o trabalho também se justifica pela necessidade de avaliar as políticas públicas desenvolvidas que visam o direito educacional da população campesina.

Considerando os elementos supracitados, este artigo tem por objetivo analisar o processo de implantação do Pronera/Proejapi - Alfabetização no estado do Piauí. O estudo tem uma abordagem epistemológica crítica, adotando a dialética "como o método que permite conhecer a realidade concreta no seu dinamismo e nas inter-relações" (Gamboa, 2012, p. 38). A investigação foi baseada em revisão da literatura e em análise documental da legislação que instituiu e orientou o Pronera no Brasil e no Piauí, e em entrevistas semiestruturadas com os sujeitos imbricados na operacionalização dessa política pública no estado (movimentos sociais e sindicais, coordenadores, professores e monitores), que atuaram no Programa de 1999 a 2003, totalizando seis colaboradores na investigação.

O resultado do trabalho apresentado neste artigo está dividido em três seções, além desta introdução. Na primeira, é apresentado um breve panorama histórico das políticas para a educação no meio rural, incluindo o Pronera como um demarcador importante da mudança de paradigma na oferta educacional do campo. Na segunda, é exposto o processo de implantação do Pronera/Proejapi no Piauí, descrevendo sua organização e revelando as dificuldades e as superações decorrentes do compromisso dos agentes com o direito à Educação do Campo. Na 
terceira e última seção, são tecidas as considerações finais do trabalho.

\section{Notas históricas sobre a educação ofertada no meio rural}

O Brasil é um país de desigualdades socioeconômicas de caráter estruturante. Nas palavras de Frigotto (2011), os descompassos da sociedade brasileira têm suas raízes no seu próprio modelo de construção histórica, pautado na “imbricação do atraso, do tradicional e do arcaico com o moderno e o desenvolvido, que potencializa a nossa forma específica de sociedade capitalista dependente e de inserção subalterna na divisão internacional do trabalho" (Frigotto, 2011, p. 24). Isto posto, destaca-se que o capitalismo dependente se expressa, no Brasil, por uma subordinação direta deste aos ditames do capital internacional, em detrimento dos interesses da classe trabalhadora e da garantia dos seus direitos sociais.

O processo de colonização do Brasil, baseado no modelo agroexportador e no trabalho escravo como aportes para o desenvolvimento do capitalismo, teve como uma de suas consequências a constituição da educação enquanto um dos direitos que vem sendo negado às classes trabalhadoras até os dias atuais (Coutinho, 2009). De acordo com Gonçalves (2017, p.
55), “a educação escolar foi sendo oferecida ao longo dos séculos no país de forma dual e deficitária, pois a um pequeno grupo foi se ampliando a escolarização, sendo permitida à maioria apenas o acesso rudimentar a leitura e a escrita". O que reforçava a exclusão dos mais pobres, garantindo às classes dominantes ou em ascensão o acesso a profissões que tinham um maior reconhecimento social.

A negação do direito à educação é, de modo geral, um fenômeno que atinge tanto as zonas urbanas quanto rurais, sendo intensificada nestas pelo desinteresse no desenvolvimento social do meio rural brasileiro, visto que "a preservação das desigualdades sociais no campo é um elemento estratégico não apenas para deprimir o preço da força de trabalho, mas para maximizar o excedente extraído da agricultura" (Sampaio Jr, 2013, p. 200), garantindo, assim, a manutenção das relações de produção que, por sua vez, são pautadas na exploração do trabalhador e no conformismo ideológico. Ademais, em seu estudo, Azevedo (2007) aponta para o alinhamento dos programas ofertados no meio rural "aos modelos políticos de desenvolvimento econômico efetivado no campo, cujas bases se fundamentavam nos interesses das classes dominantes" (Azevedo, 2007, p. 145), condicionando a oferta da educação no meio rural à 
manutenção das relações de dominação tanto em âmbito político quanto econômico.

Nesse sentido, nota-se que, à medida que os interesses tanto do capital quanto do Estado são conservados, as demandas dos reais sujeitos do processo, ou seja, dos povos rurais, são marginalizadas. Nas palavras de Calazans (1993, p. 20), o desenvolvimento do ensino rural "através da história reflete, de certo modo, as necessidades que foram surgindo em decorrência da própria evolução das estruturas agrárias no país", demonstrando que a educação ofertada no meio rural se constituía enquanto um apêndice da política educacional brasileira, limitandose à oferta de programas pontuais e descontínuos com baixos níveis de aproveitamento, bem como pela instituição de salas unidocentes, fomentando não só os processos de exclusão, mas também as tensões sociais no campo.

No que concerne às tensões no meio rural, aponta-se que a exclusão dos camponeses não se deu sem resistência. Ribeiro (2013, p. 185) aponta que, "no início dos anos de 1980, a ditadura militar já não conseguia sufocar os conflitos que decorrem das relações contraditórias entre capital e trabalho, no campo". Nesse período, destaca-se a criação do Movimento dos Trabalhadores Sem Terra
(MST), cuja concepção de educação sedimenta-se no campo prático e teórico, podendo ser entendida enquanto uma ação primeira para garantir a escolarização de crianças, jovens e adultos com pouca ou nenhuma instrução, residentes em áreas de acampamento ou assentamento (Caldart, 2012).

Além do mais, salienta-se que o sentido que a escola e o acesso à educação têm para os integrantes do movimento sem-terra não se restringem aos signos construídos historicamente pela sociedade burguesa. A educação, para este segmento da sociedade, toma como norte o desenvolvimento sustentável do campo e a superação do modo de produção capitalista, compreendendo que a escola "é uma estratégia para garantir inicialmente acesso à educação, mas fundamentalmente para a universalização de uma educação de classe na perspectiva da emancipação humana" (D'Agostini, 2012, p. 458), elemento indispensável para o processo de transformação da sociedade.

As experiências acumuladas pelo MST contribuíram diretamente para a construção da Política de Educação do Campo, que, por sua vez, "nasceu como crítica à realidade da educação brasileira, particularmente à situação educacional do povo brasileiro que trabalha e vive no/do campo" (Caldart, 2010, p. 39). No que 
concerne a essa crítica, a autora explica que

nunca foi a educação em si mesma porque seu objeto é a realidade dos trabalhadores do campo, o que necessariamente a remete ao trabalho e ao embate entre projetos de campo que têm consequências sobre a realidade educacional e o projeto de país (Caldart, 2010, p. 39).

Isso denota uma ruptura com as concepções de educação ofertadas pelo Estado para o meio rural, que foram forjadas por sujeitos históricos no interior da luta dos movimentos sociais e sindicais rurais.

A Educação do Campo é um conceito em construção, que não foi planejado, mas que nasceu da potência educativa dos movimentos sociais e da luta pela escolarização dos povos rurais, mais especificamente dos residentes em áreas de assentamento ou acampamento. É válido pontuar que a gênese dessa luta não representa em si a totalidade do que veio a se constituir enquanto conceito de Educação do Campo, sendo, contudo, uma parte fundante e indissociável de sua história. Para um melhor entendimento desse ponto, tem-se que, nas palavras de Freitas (2011, p. 41), “embora as expressões Educação do Campo e Educação na Reforma Agrária tenham surgido simultaneamente, elas seriam diferentes, mas complementar-se-iam”. A diferença central entre esses dois conceitos está nos respectivos lócus de desdobramento, enquanto a Educação na Reforma Agrária se vincula às ações que se desenvolvem em assentamentos e acampamentos, a Educação do Campo volta-se para o atendimento da população rural como um todo.

Para exemplificar como as experiências acumuladas pelo MST contribuíram diretamente para a construção da Política de Educação do Campo, aponta-se que, segundo Molina (2003, p. 50), foi no I Encontro Nacional das Educadoras e Educadores da Reforma Agrária (ENERA), realizado com o objetivo de avaliar o trabalho que vinha sendo desenvolvido pelo setor de educação do MST, estruturado em 1987, que "gestou-se o que viria a se tornar uma das primeiras políticas públicas de Educação na Reforma Agrária (Pronera)". No I ENERA, o MST reuniu-se na Universidade de Brasília (UNB), juntamente com membros do Fundo das Nações Unidas para a Infância (Unicef), da Organização das Nações Unidas para a Educação (Unesco) e da Conferência Nacional dos Bispos do Brasil (CNBB).

No encontro, foram discutidas questões relacionadas com as problemáticas vivenciadas no âmbito dos assentamentos e acampamentos, sendo 
estas de caráter social, político, econômico

e educacional. Iniciou-se, assim, um intenso processo de articulação com as universidades brasileiras para a elaboração de referenciais que permitissem a escolarização dos assentados. Segundo Félix (2015, p. 36), a discussão em torno da temática culminou com “a elaboração de um documento proposta, apresentado no III Fórum do Conselho de Reitores das Universidades Brasileiras (CRUB)”. A proposta das universidades priorizava a alfabetização de Jovens e Adultos, tendo em vista o alto índice de analfabetismo em áreas de assentamento, enquanto a política de fundos para o financiamento da educação focalizava o investimento no ensino fundamental regular, excluindo a EJA. No tocante a essa prioridade, Molina (2003, p. 53) pontua que

O Pronera foi formalizado como estratégia política para incluir jovens e adultos assentados excluídos das políticas públicas de educação do governo Fernando Henrique Cardoso (1995-2002), que mais se ocupou em racionalizar gastos públicos e reformou o ensino a partir de uma visão economicista. As principais diretrizes de sua reforma desconcentraram o financiamento e as competências de gestão relativas ao ensino básico em favor de estados e municípios e focaram-nas no ensino fundamental (crianças e adolescentes). Ao operacionalizar tais diretrizes sob contenção do gasto público, reduziu a prioridade a ser conferida à universalização e a melhoria da qualidade do ensino fundamental de crianças e adolescentes em quase exclusividade para a faixa etária de 7 a 14 anos. Jovens e adultos analfabetos ou pouco escolarizados, não estavam entre as prioridades da política educacional daquele governo.

A ação do governo FHC de priorizar o ensino fundamental encontrou lastro na política neoliberal adotada por aquele governo, em que o foco estava na diminuição dos gastos públicos com educação, priorizando uma etapa da educação básica e deixando outras etapas e modalidades, como a EJA, em condições ínfimas de funcionamento, cabendo aos estados e municípios a realização de "manobras" para garantir a oferta, mesmo que mínima, das modalidades excluídas do cômputo da política de fundos. É válido pontuar que essa ação do governo federal trouxe inegáveis consequências para a garantia do direito à educação, principalmente para as populações jovens e adultas, tendo em vista a desresponsabilização direta do Estado para com a sua oferta.

Diante do contexto de negação do direito à educação para os povos do campo, materializado, dentre outros indicadores, por meio de estatísticas que demonstram o alto índice de analfabetismo e a distorção idade-série, os movimentos sociais e sindicais rurais levaram para a cidade as problemáticas que penalizavam a referida população. Em linhas gerais, os 
sujeitos históricos envolvidos diretamente com a luta criticavam a "desigualdade do acesso à escola, apontando ainda as dificuldades com relação aos conhecimentos teóricos e práticos, distanciados da realidade e dos interesses dessa população" (Paiva, 2004, p. 104), dando início à luta por uma Política Pública de Educação do Campo, contrahegemônica ao projeto capitalista e burguês de educar.

A mobilização dos movimentos sociais em torno da institucionalização do Pronera é um ponto fundante para garantia da sua regulamentação. Contudo, não se pode perder de vista a conjuntura social, política e econômica do país naquela época, dado que seus meandros tiveram influência direta no processo de implantação desse Programa no âmbito do governo federal. As denúncias do Movimento acerca das violências no campo, em voga por conta dos massacres de Corumbiara (1995) e El dourado dos Carajás (1996), juntamente com os baixos índices de escolarização revelados pelo I Censo Nacional da Reforma Agrária (Bergamasco, 1997), concluído em 1996.

Tais fatores contribuíram para que Fernando Henrique Cardoso fosse pressionado direta e indiretamente pela população, que estava sensibilizada com a situação dos sem-terra, pelo interesse político na sua possível reeleição, pelos organismos internacionais, que exigiam a elevação dos índices sociais para a concessão de empréstimos, e/ou por outros fatores inerentes ao jogo políticoeconômico. Em vista de tais tensionamentos, em 16 de abril de 1998, por meio da Portaria $n^{0}$ 10/98 do extinto Ministério Extraordinário de Política Fundiária, o Ministro Raul Jungmann institucionalizou o Programa Nacional de Educação na Reforma Agrária (Pronera).

Como uma estratégia de fortalecimento, o Programa nasce vinculado à política de Reforma Agrária. Isto posto, importa pontuar que, em comparação com outros programas educacionais voltados para o meio rural, cuja ligação com o Ministério da Agricultura guardava estreitas relações com a modernização do campo e o fortalecimento das técnicas agrícolas estadunidenses, o Pronera representa um avanço qualitativo no processo de valorização tanto dos povos rurais quanto da agricultura familiar. $\mathrm{Na}$ Portaria $n^{\circ} 10 / 98$, que o instituiu, este foi caracterizado enquanto uma política de inclusão social que tinha o objetivo de atender à demanda por educação nos assentamentos rurais. A proposta, apresentada no referido documento, vinculava o Programa à política de 
Reforma Agrária desenvolvida pelo governo federal, pontuando que este visava

...Atender à demanda educacional dos assentamentos rurais, dentro de um contexto de Reforma Agrária prioritário do Governo Federal, de assentar um trabalhador rural em um lote de terra, provendo-lhe as condições necessárias ao seu desenvolvimento econômico e sustentável (Incra, 1998).

Na linha do que havia sido definido, consta no primeiro Manual de Operações do Pronera (1998) o objetivo geral de "fortalecer a educação nos assentamentos de Reforma Agrária, utilizando metodologias específicas para o campo, que contribuam para o desenvolvimento rural sustentável no Brasil" (Incra, 1998, p. 10). Nessas palavras, vinculava-se a educação para os povos rurais a um determinado projeto de desenvolvimento do campo brasileiro, o que favorecia a manutenção da lógica do Programa enquanto uma política de resistência e fortalecimento das áreas de Reforma Agrária.

A concepção educacional do Programa vincula-se às questões problematizadas e forjadas no âmbito do movimento de Educação Popular, iniciado em meados da década de 1950, definido, nas palavras de Freitas (2011, p. 38), enquanto um "conjunto de práticas que se realizam e se desenvolvem dentro do processo histórico no qual estão imersos os setores populares". Partindo desse entendimento, corrobora-se a ideia de que o Pronera não se resume à escolarização com um fim em si mesma, mas constitui-se enquanto uma política de Educação do Campo que busca garantir o direito à educação ao assumi-la como uma das pautas de luta da classe trabalhadora, com ênfase na formação crítica de seus sujeitos e no fortalecimento do campo enquanto um espaço de vida e resistência.

No entanto, não se pode deixar de considerar que o Programa está inserido dentro de uma economia capitalista, logo, desdobra-se dentro dos limites das possibilidades postas. Nesse sentido, é válido ressaltar que a materialização das propostas de acordo com os pressupostos da política acima depende, dentre outros fatores, da qualidade da oferta e da efetiva participação dos movimentos sociais e sindicais do campo, bem como dos representantes das instituições de ensino e demais membros da sociedade civil interessados em fortalecer a luta da classe trabalhadora. Não obstante, aponta-se que o financiamento é uma condição basilar para a execução das políticas públicas, conservando uma estreita relação com a garantia dos direitos sociais.

No que concerne ao financiamento do Pronera, alguns pontos precisam ser 
elencados, tais como: a resistência, por parte da União, em incluí-lo no orçamento federal; os baixos índices tanto de dotação orçamentária quanto de execução dos recursos; e os entraves no repasse destes para as universidades (Di Pierro, 2002; Molina, 2003). Isto posto, partindo da compreensão de que as condições de financiamento se relacionam com o lugar que a política ocupa na esfera governamental, aponta-se, com base nos estudos de Di Pierro (2000; 2002), Marialva (2011) e Paiva (2013), que o direito à educação para os povos rurais continuava a ser marginalizado no âmbito das políticas educacionais.

Tendo em vista as discussões que se desdobraram nesta seção do artigo, bem como a necessidade de apreensão das "contradições e tensões que estão na realidade" (Caldart, 2010, p. 38), serão apresentadas, na próxima seção, as questões referentes à execução do Pronera no estado do Piauí, objetivando compreender o movimento entre a garantia legal do direito à educação e sua negação no que concerne às condições de materialização da política, buscando contribuir com o balanço da história da Educação do Campo e com a construção de novas possibilidades.

\section{O Proejapi no contexto do Pronera}

Em meados do ano de 2001, objetivando ampliar o atendimento educacional no meio rural, o Incra e a Fundape, com a interveniência da UFPI, celebraram entre si um convênio para a execução de um curso de alfabetização de jovens e adultos residentes em assentamentos piauienses selecionados pela Fetag-PI e pelo MST-PI, com base no índice de analfabetismo, no interesse da comunidade e na capacidade de mobilização dos seus moradores. Após a publicação do termo de convênio no Diário Oficial da União, no dia 6 de dezembro de 2001, os professores universitários envolvidos com a coordenação do Projeto, juntamente com os membros dos movimentos sociais, deram início ao processo de seleção dos integrantes da equipe pedagógica e mobilização da demanda.

No convênio estava previsto o atendimento a 1.000 alunos, residentes em 35 projetos de assentamentos, bem como a seleção de 50 monitores, 5 coordenadores locais e 5 alunos universitários. Nesse formato, as turmas seriam compostas por, no máximo, 20 alunos (Incra, 1998). Contudo, tendo em vista o fenômeno da evasão escolar, recorrente tanto nas turmas do Pronera quanto de outros projetos voltados para a educação de jovens e adultos, os coordenadores do Projeto 
ampliaram, de forma indireta, a meta de atendimento do curso para 1.200 educandos, fazendo-se necessário o aumento do número de pessoas implicadas na composição da equipe pedagógica. Nestes termos, seguindo a lógica de acompanhamento das turmas de alfabetização do Pronera, foram selecionados: 6 alunos universitários, 6 coordenadores locais e 60 monitoresalfabetizadores. A mobilização da demanda nos assentamentos de Reforma Agrária, no estado do Piauí, e o cadastro dos educandos, desdobraram-se após a seleção dos membros da equipe pedagógica.

Ao término desse processo, haviam se matriculado no curso de alfabetização 1.272 jovens e adultos de 40 projetos de assentamento, correspondendo a uma média de 21,5 educandos por turma, superando tanto o número de alunos estimado pelos coordenadores do Projeto quanto a quantidade de assentamentos beneficiários (Incra, 2003). Nesse contexto, o número de matrículas excedeu a quantidade ofertada e prevista pelo fato de que, aproximadamente, $70 \%$ da demanda em potencial não havia sido atendida na primeira etapa do Pronera/Proejapi.

O total de alunos foi distribuído em 60 turmas de alfabetização localizadas nos projetos de assentamento, sendo 8 coordenadas pelo MST e 52 pela Fetag. Os locais de funcionamento de tais turmas variavam de acordo com as condições estruturais dos assentamentos e capacidade de mobilização destes, fazendo-se os mais recorrentes: a casa do monitor, o galpão, a sede da associação, o colégio municipal ou outros. Conforme os dados do relatório final de avaliação das ações do Pronera/Proejapi - meta alfabetização, tem-se que $59 \%$ das salas de aula funcionavam em locais improvisados na comunidade, e outros $41 \%$ em prédios escolares.

Os limites estruturais exigiram a mobilização dos parceiros e dos coordenadores do Projeto em torno da garantia das condições materiais necessárias para o funcionamento das turmas, conforme dados do relatório final:

Para conseguir equipar as salas, a coordenação do Projeto e Representantes dos Movimentos sociais (MST-PI e Fetag-PI) e Sindicatos dos Trabalhadores Rurais articularam-se com Prefeituras, Associação de assentados, Secretarias de Estado e outros, para obtenção de equipamentos como carteiras, lampiões, quadros, óleo para manutenção de motores geradores de energia, etc. Muitas destas solicitações tiveram êxito em seu atendimento. Em alguns casos, a própria comunidade local contribuiu para a melhoria da estrutura das salas de aula, e nas situações mais carentes o Projeto viabilizou a aquisição de botijão de gás e lampiões, quadros de 
giz, sob pena de as atividades não serem iniciadas (Incra, 2003, p. 18).

Nas discussões que giram em torno da luta por uma educação de qualidade, as condições estruturais tanto da escola quanto da sala de aula constituem um aspecto central da materialização efetiva do direito à educação, sendo um elemento basilar no desenvolvimento das práticas pedagógicas. No entanto, corroborando o entendimento de que o Programa foi iniciado "a partir do campo das ideias para depois buscar compreender a materialidade existente" (Sousa, 2015, p. 91), apreendese que as condições materiais para o funcionamento das turmas de alfabetização no Piauí não estavam dadas, o que gerou a necessidade de um processo de articulação com diferentes parceiros para tentar garantir pelo menos o mínimo necessário para o desenvolvimento das atividades, conforme depoimento a seguir:

Dentro do projeto não era previsto a questão de infraestrutura, a ideia era que aulas acontecessem nos acampamentos com estrutura própria do Estado, ou seja, tinha aquela visão da parceria. Se o município tivesse uma sala, a gente fazia uma parceria, ou então, aconteciam em uma cabana, nos barracões. $\mathrm{Na}$ maioria dos assentamentos não tinha energia, aí a gente conseguia adquirir uns lampiões para garantir que as aulas acontecessem normais (Coordenador do Setor de Educação do MST no PI, 7 de junho de 2019, Centro de treinamento da EMATER).
Isto posto, enfatiza-se que as condições para o funcionamento do Projeto só eram enfrentadas após o conveniamento e mediante a mobilização dos próprios movimentos sociais e envolvidos com a operacionalização da proposta. Nesse sentido, concorda-se com Sousa (2015, p. 92) ao afirmar que os esforços que poderiam ter sido investidos nas questões relacionadas à qualidade do Projeto foram direcionados "para dar conta daquilo que era de responsabilidade do Estado". Além do mais, problematiza-se que, pelo fato de o Projeto não prever um recurso para infraestrutura, a garantia de seu fortalecimento, em termos de condições materiais para o desenvolvimento de outros cursos ou projetos voltados para o público beneficiário da Reforma Agrária, ficou prejudicada ou inexistiu.

De um modo geral, as condições precárias de funcionamento nas salas de aula, tanto no que concerne ao local quanto à infraestrutura, foi um dos fatores que contribuiu para o abandono do curso por parte de um número significativo de alunos: 40,7\% evadiram das turmas de EJA (Incra, 2003, p. 26). Esse fato indica a importância da infraestrutura para os processos de garantia do direto à educação, os quais não se restringem à oferta, visto que, sem as condições concretas de acesso 
e permanência, a negação desse direito é reafirmada.

Diante do exposto, importa salientar que "o impacto das políticas sociais implementadas pelo Estado capitalista sofre o efeito de interesses diferentes expressos nas relações necessárias de poder" (Hofling, 2001, p. 35), sendo indispensáveis os constantes tensionamentos da classe trabalhadora e, portanto, da ação dos movimentos sociais para garantir e ampliar seus direitos.

No que concerne aos pressupostos teórico-metodológicos que perpassaram as atividades do Pronera/Proejapi - meta alfabetização, aponta-se que aqueles tomavam como base os pressupostos da educação libertadora de Paulo Freire (1968), tendo como um dos eixos de referência a articulação entre as atividades de educação formal, a realidade vivenciada nos assentamentos e os processos de emancipação política (Incra, 2003).

...O Pronera tem esse diferencial, o debate político, que os sujeitos que passam por ele mesmo no processo de alfabetização e de escolarização você consegue ver isso grandioso, pessoas que não conseguiam ler um texto que saem dali lendo, eu acho que isso é uma grande vitória, a questão do aprendizado do mundo da leitura, mas também do aprendizado político, é um espaço diferenciado que permite não só o monitor falar, mas o educando se sentir parte do processo, então, eu considero isso um grande avanço (Monitora;
Coordenadora Local, 5 de julho de 2019, UFPI).

No que diz respeito à questão do debate político, aponta-se que as discussões em sala de aula deveriam considerar os conhecimentos e vivências dos trabalhadores, de modo que houvesse uma problematização, reflexão e ação concreta sobre a realidade dos assentamentos (Incra, 2003). Para tanto, a proposta metodológica do projeto pautouse na "organização do saber a partir de situações-problema, temas e palavraschaves fundamentados na história e práticas do cotidiano da comunidade e dos indivíduos que a compõem” (Incra, 2003), o que pressupunha o conhecimento do espaço, da realidade e das vivências dos educandos.

O Pronera tem uma importância muito grande, ele trabalha a educação voltada para a realidade dos assentamentos, para a realidade do campo, e não aquela educação que é dada na cidade $e$ no assentamento da mesma forma (Asseguradora, 4 de julho de 2019, sede do Incra no Piauí).

Historicamente, a educação ofertada pelo Estado no meio rural não considerava os saberes e a cultura dos camponeses, sendo trabalhada de forma desconexa da realidade vivenciada por estes, ao passo que reforçava a ideia da cidade como sinônimo de desenvolvimento. Nesse sentido, considerando que "nenhum 
método pedagógico será efetivo se não atingir o mundo de preocupação, de necessidade e os saberes e experiências que as crianças, jovens e adultos trazem do aprendizado na vida para o espaço escolar" (Frigotto, 2011, p. 38), questiona-se em que medida o modelo educacional supracitado contribui para a construção dos processos de significação e transformação da realidade dos educandos. Isto posto, identificam-se, na proposta metodológica do Pronera, as possibilidades de significação da realidade e sua consequente transformação.

A operacionalização da meta de alfabetização contemplava três momentos distintos, indissociáveis e concomitantes: 0 processo de escolarização dos jovens e adultos; as capacitações em serviço; e o acompanhamento pedagógico das salas de alfabetização. Nesse sentido, aponta-se que a lógica de operacionalização do Projeto pressupunha um constante deslocamento entre a Capital do estado (Teresina) e os projetos de assentamento. Dentre as atividades, destacam-se as capacitações em serviço dos membros da equipe pedagógica, mais especificamente dos estudantes universitários, monitores e dos coordenadores locais, bem como o acompanhamento pedagógico das turmas de alfabetização que, dentre outros aspectos, objetivavam garantir o processo de escolarização dos educandos de acordo com a proposta metodológica do Projeto (Incra, 2003). O processo de escolarização dos educandos, as capacitações em serviço da equipe pedagógica, alunos universitários, coordenadores locais e monitores, tomavam como base os pressupostos da pedagogia libertadora de Freire (1968).

O acompanhamento das atividades pedagógicas visava a reorientação da prática que estava sendo desenvolvida pelo monitor, possibilitando-o "incorporar novas habilidades e novos conhecimentos teóricos" mediante uma avaliação crítica do seu fazer em sala de aula (Molina, 2003, p. 94). Tomando como base o relatório de avaliação do Incra, os coordenadores locais faziam visitas de acompanhamento e (re)orientação das atividades pedagógicas e operacionais a cada uma das salas de aula que compunham a sua coordenação, com o objetivo de preencher o relatório com os resultados e as dificuldades do processo de escolarização. Em seguida, juntamente com o aluno universitário, eram traçadas estratégias para subsidiar a prática docente dos monitores.

Para o melhor acompanhamento das turmas, estas foram distribuídas em seis coordenações locais, tendo como um dos critérios a proximidade entre os 
assentamentos e as respectivas coordenações. Considerando o disposto no Manual de Operações (2001), cada coordenação, composta por um coordenador local e sob a responsabilidade de um aluno universitário, deveria acompanhar o trabalho de 10 monitores e o desenvolvimento de, em média, 200 educandos. $\mathrm{O}$ processo de acompanhamento pedagógico e as capacitações em serviço constituíam-se enquanto espaços que, além de formativos, eram fundamentais para o processo de avaliação e mediação das dificuldades identificadas no exercício das funções desempenhadas tanto por monitores quanto por coordenadores locais.

O Pronera também foi muito importante pela questão da capacitação, você não chegava lá igual se contratava um professor qualquer, essas pessoas eram indicadas dentro daquele nível de conhecimento que elas já tinham naquela área, passavam por um processo de formação, de preparação e tinham todo um acompanhamento (Coordenadora Local, 7 de junho de 2019, Centro de Formação da EMATER).

A importância dessas atividades, principalmente no que concerne à execução da proposta pedagógica, relacionava-se diretamente ao baixo nível de escolaridade dos monitoresalfabetizadores. Embora a escolaridade fosse um dos principais critérios a ser considerado no processo de seleção, "nas áreas de assentamento não havia pessoas com uma formação adequada que dessem conta de assumir esta tarefa" (Sousa Sobrinho, Morais \& Paixão, 2017, p. 89). Desse modo, é possível depreender que "os monitores-alfabetizadores selecionados pelo Projeto tinham nível de escolaridade que variava do Ensino Fundamental incompleto ao Nível Médio completo, tanto a nível de magistério como científico" (Incra, 2003), sendo que, do total: $72 \%$ tinham o Fundamental completo; 9,3\% o incompleto; 13,8\% o Ensino Médio completo, dos quais apenas 6,9\% tinham habilitação para trabalhar com o magistério; e outros $4,8 \%$ tinham o Ensino Médio incompleto (Incra, 2003).

Os processos formativos se davam de forma simultânea, ou seja, a alfabetização de jovens e adultos se desdobrava de forma concomitante ao processo de capacitação e elevação da escolaridade dos monitores. Isto posto, partindo-se da compreensão de que a formação do educador é um aspecto fundamental para o desenvolvimento do trabalho em sala de aula, questiona-se em quais condições de ensino-aprendizagem se desdobrou o processo de alfabetização dos educandos, e até que ponto os monitores-alfabetizadores conseguiram compreender e executar a proposta metodológica do Projeto. 
Inicialmente, os monitoresalfabetizadores tiveram dificuldades no trabalho com os educandos e na aplicação da proposta pedagógica. Assim, sua participação nas capacitações em serviço e a dedicação ao trabalho configuraram-se como pontos centrais para a melhoria das suas práticas educativas. Nessa perspectiva, Sousa Sobrinho, Moraes e Paixão (2017, p. 123) afirmam que, no âmbito do Pronera/Proejapi, após as experiências de capacitação, houve "um grande progresso dos monitores tanto em relação aos níveis de leitura e escrita quanto em relação à própria compreensão da realidade". Embora os dados apontem um avanço dos monitores no que concerne ao desenvolvimento do trabalho pedagógico em sala de aula, a baixa escolaridade destes precisa ser considerada no processo de avaliação dos resultados, tendo em vista as suas implicações no que tange à qualidade do processo de alfabetização dos educandos.

No que tange às condições subjetivas de desenvolvimento do trabalho do monitor nas turmas de alfabetização, as informações dispostas no relatório final de avaliação das ações do Pronera/Proejapi II - meta alfabetização, apontam que o processo de seleção dos monitores contribuiu para que estes desenvolvessem uma noção de pertencimento, decorrente, dentre outros fatores, do processo de valorização e do desejo de ver aquela ação concretizada, compreendendo a importância da educação para o desenvolvimento social e econômico das suas localidades (Incra, 2003). Além do mais, o fato de serem assentados, tal qual os educandos, é um aspecto que deve ser considerado como positivo no processo de construção do conhecimento.

Ser morador do assentamento era um critério de aproximação dos educandos com os educadores (Funcionária do Incra, 4 de julho de 2019, UFPI).

O fato de o monitor ser alguém do próprio assentamento, eu acho que isso trazia um benefício muito grande, pela própria efetividade que existia entre eles (Coordenadora Pedagógica, 5 de julho de 2019, UFPI).

Tomando como base os depoimentos da funcionária do Incra e da coordenadora pedagógica, assinala-se que $\mathrm{o}$ fato de $\mathrm{o}$ monitor ser alguém do próprio assentamento contribuía diretamente para o desenvolvimento da proposta pedagógica, visto que a alfabetização era "favorecida pelo fato de os jovens educadores em processo de formação compartilharem com os educandos a mesma linguagem, cultura e história de luta" (Andrade \& Di Pierro, 2004, p. 28). Além disso, destaca-se que tais aspectos têm como linha proximal as significações atribuídas tanto pelos 
monitores quanto pelos educandos ao processo de escolarização.

Nesse sentido, aponta-se que tais significações podem estar relacionadas com a dedicação ao trabalho e enfrentamento das dificuldades que se apresentavam no decorrer da execução da proposta. Em entrevista, o coordenador do Projeto no âmbito da Universidade pontuou o seguinte:

Sempre tinham problemas, sempre! Mas, eu acho que diante do ganho, do resultado social do projeto, eu acho que os problemas foram muito pequenos em relação a tudo isso, as dificuldades foram muito pequenas (Coordenador, 21 de junho de 2019, UFPI).

Quando questionado acerca dos fatores que tinham contribuído para a minimização das problemáticas, este destacou a "força dos assentados". Para o coordenador:

Havia muita vontade e muita determinação da parte deles! Por exemplo, os monitores eram semialfabetizados, né? Às vezes eles se superavam na dedicação ao trabalho. Ah, mas era porque eles recebiam uma bolsa? Não! Além disso, eu acho que eles tinham mesmo uma causa, era uma causa que eles compravam, a causa da educação, da luta por escolaridade; $e$ isso era muito presente (Coordenador, 21 de junho de 2019, UFPI).

Tendo em vista as afirmações do coordenador, é possível apreender que os significados atribuídos pelos assentados ao processo de escolarização foram fatores determinantes para a superação das dificuldades que iam se apresentando no decorrer do processo de operacionalização do Projeto. No que concerne aos problemas, mediante a análise tanto do processo completo, referente ao convênio da meta de alfabetização, quanto das entrevistas realizadas com os membros da equipe pedagógica, destaca-se o seguinte: as precariedades estruturais dos assentamentos; as burocracias dos trâmites processuais; não liberação das parcelas acordadas no plano de trabalho; e o consequente atraso das atividades pedagógicas, tais como os processos de acompanhamento e as capacitações.

A execução das atividades pedagógicas dependia diretamente da liberação e do repasse dos recursos. No âmbito do Incra, a liberação dos recursos e o seu respectivo repasse para a Fundape era precedido de uma dinâmica de solicitação de pagamento feita pelo(a) assegurador(a) do Pronera ao ordenador de despesas do Incra, junto a sua respectiva autorização. É válido pontuar que tal liberação dependia, dentre outros fatores, da disponibilidade orçamentária daquela Autarquia. No contexto da Fundação, o repasse de recursos para a Universidade dependia, também, de uma solicitação de 
pagamento, feita pelo coordenador geral do Projeto, com base em um modelo disponibilizado pela própria Fundape.

Tanto o valor das parcelas quanto as datas de liberação estavam previstos no plano de trabalho, elaborado de acordo com o cronograma de execução das atividades do curso. No entanto, mediante a análise documental, observou-se que, além das parcelas não terem sido repassadas nas datas pactuadas, houve situações em que o recurso previsto não foi liberado em sua totalidade.

Os problemas referentes à liberação das parcelas nos prazos pactuados no plano de trabalho trouxeram prejuízos para o processo de alfabetização tanto no que concerne ao desenvolvimento de uma ação qualitativa, quanto na execução do objeto de conveniamento dentro do prazo estabelecido inicialmente. Em vista dessas questões, no decorrer do processo de operacionalização do convênio em análise, foram publicados quatro termos aditivos. $\mathrm{O}$ primeiro decorreu da necessidade de cobertura orçamentária para a liberação da quarta parcela, e os outros três, da necessidade de prorrogação da vigência do convênio.

A prorrogação da vigência de um convênio é consequência do não cumprimento dos prazos estabelecidos no plano de trabalho, dado que a não liberação dos recursos compromete a execução do objeto. No caso do Pronera/Proejapi, isso interferiu, sobremaneira, nos processos de acompanhamento das salas de alfabetização, porque a equipe pedagógica passava muito tempo sem viajar, prejudicando o andamento das ações. Destaca-se que os pedidos de prorrogação estavam relacionados com os problemas no desenvolvimento das atividades pedagógicas e formativas.

O fato de haver atraso na liberação dos recursos compromete todo um programa definido de execução daquele projeto educativo, né? Então, uma das grandes dificuldades, é exatamente a liberação de recursos nos prazos definidos nos planos de trabalho. Não só nos prazos, mas também em montante de recurso, porque, como eu te falei, tem esses contingenciamentos que o governo federal estabelece a partir das necessidades postas nos orçamentos da União, e esses cortes terminam comprometendo a execução na forma como ela foi planejada (Funcionária do Incra, 4 de julho de 2019, UFPI).

A liberação de uma parcela para a execução de um determinado objeto é antecedida de trâmites burocráticos e processuais que podem prejudicar $\mathrm{o}$ alcance das metas. Nesse sentido, chamase a atenção para o engessamento imposto pela legislação que regulamenta os princípios da administração pública, com ênfase nas diretrizes que normatizam a operacionalização de um convênio, visto que, em nome do princípio da legalidade, 
pequenos erros podem trazer sérios prejuízos, tanto no âmbito da continuidade quanto no da qualidade das ações desenvolvidas. Isto posto, destaca-se que os atrasos na liberação das parcelas foram apontados como um dos principais entraves para a execução da proposta.

O atraso na liberação das parcelas comprometia não só o cronograma de execução, mas a qualidade das atividades. Disso depreende-se que as precarizações referentes à suficiência dos recursos e de seu processo de liberação dificultavam ainda mais a execução da proposta, e colocavam em xeque as condições de sua realização de modo qualitativo.

Tinham algumas dificuldades, mas, da parte dos movimentos sociais, sempre teve uma atuação de buscar a garantia da execução do Programa, dos direitos já estabelecidos a partir da conquista que eles tiveram de ter um programa voltado para a educação na Reforma Agrária (Funcionária do Incra, 4 de julho de 2019, UFPI).

Esse depoimento, de uma funcionária do Incra oferece indícios de que tais esforços podem estar relacionados com os significados construídos em torno das possibilidades formativas dispensadas pelo Pronera.

Só sabe o que isso significa quem nasceu lá na roça, sem ter tido a oportunidade de no tempo certo estudar. No tempo certo que eu digo, é fazer aquele estudo regular com todas as condições, como muita gente tem oportunidade (Monitora; Coordenadora Local, 5 de julho de 2019, UFPI).

Em vista dos diversos fatores de ordem estrutural que perpassam a vida dos povos rurais, como os enfrentamentos diários e a luta por sobrevivência, compreende-se que o significado atribuído à educação ofertada pelo Pronera estava relacionado com os processos de negação do direito à educação para os povos do campo. Nesse sentido, problematiza-se que o fato de os assentados não terem acessado ou concluído outros processos educacionais, bem como a falta de perspectiva sobre outras possibilidades de acesso, pode ter contribuído para a construção de diferentes significados relacionados à possibilidade destes de iniciarem o seu processo de escolarização.

O pobre, o camponês, ele é muito esquecido institucionalmente. E o Pronera vem com esse propósito de trazer essa pessoa para que ela tenha acesso... Foi uma conquista que ainda hoje envereda pelo Brasil inteiro, levando educação, escolarização e qualificação para aquelas pessoas que não teriam acesso de outra forma (Coordenador do Setor de Educação do MST no PI, 7 de junho de 2019, Centro de treinamento da EMATER).

...O Pronera/Proejapi ainda tem um diferencial, ele foi a locais que a ação do Estado não chegaria nunca, que a mão do Estado não estava presente mesmo, porque se você pensar nos lugares mais distantes desse Estado, nos lugares que eu 
nunca imaginei, e você pensar que lá naquele assentamento, em uma cidade tão distante, estava funcionando uma turma de alfabetização ou de escolarização com assentados estudando, essa é uma grande conquista (Coordenadora Pedagógica, 5 de julho de 2019, UFPI).

Tais relatos corroboram a ideia de que o compromisso com a execução da proposta estava relacionado às significações do acesso a um direito historicamente negado. Nesse sentido, aponta-se que os membros da equipe pedagógica, mais especificamente os ligados à realidade dos assentamentos, em contraposição à negação das condições concretas de realização da proposta, empreendiam esforços e recursos próprios para garantir a continuidade do curso, dadas as significações atribuídas no contexto.

...Hoje nós temos resultados, temos sementes que hoje são professores, que são qualificados, que são especialistas e estão ganhando seu salário! E isso é uma riqueza, ou seja, não foi prejuízo, a fome e a sede que a gente passou, já esquecemos! (Coordenador do Setor de Educação do MST no PI, 7 de junho de 2019, Centro de treinamento da EMATER).

O depoimento do Coordenador do Setor de Educação do MST sintetiza a importância que o Pronera/Proejapi teve para a democratização do acesso à Educação do Campo no Piauí, e demarca a necessidade de luta contínua pela implementação de políticas públicas que viabilizem o direito educacional da população campesina.

\section{Considerações finais}

O Pronera é resultado de lutas demandadas pela classe trabalhadora do campo em seus aspectos políticoeducacionais. Esse Programa também foi uma resposta propositiva para o enfrentamento de um processo histórico de negação do direito à educação para os povos do campo, expresso nos índices de analfabetismo, de evasão escolar e de distorção idade-série, evidenciados nos dados educacionais brasileiros. O estudo possibilitou o entendimento de que o Programa tem suas bases constitutivas no processo histórico de concentração fundiária e precarização das condições materiais de viver e trabalhar no campo, sendo pautado e construído pelos movimentos sociais e sindicais com base em suas concepções e experiências educacionais.

Portanto, o Pronera como política pública de Educação do Campo, assume características diferenciadas de outras políticas voltadas à população que vive no meio rural no que se refere ao seu processo de construção, que envolveu a participação efetiva dos movimentos sociais e sindicais 
na definição do seu formato, mediante a presença nas esferas deliberativas do Programa. Ademais, o fato de o Pronera ter se desenvolvido em parceria com movimentos sociais e universidades, qualificou seu processo de implementação, assim como potencializou os estudos sobre a realidade educacional da população campesina, elementos estes importantes para a melhor compreensão e intervenção nesse espaço, no sentido de ampliar e efetivar direitos educacionais.

No contexto histórico de negligência do Estado para com a educação no meio rural, o Pronera representou uma mudança de caráter qualitativo, no que concerne à construção e à concepção dos aspectos político-pedagógicos, teóricometodológicos e operacionais. Em termos quantitativos, na esteira do acúmulo de suas experiências e dos constantes tensionamentos dos movimentos sociais e sindicais do Campo, houve uma ampliação na oferta de cursos apoiados pelo Pronera e um processo de territorialização da Educação do Campo na esfera do Estado, o que contribuiu para o alargamento das possibilidades formativas dos povos do campo. No entanto, na análise das questões relacionadas ao financiamento do Programa, inserido em um modelo organizacional em que os interesses da classe dominante se fazem hegemônicos, observou-se que a oferta educacional para os povos rurais continuou sendo negligenciada pelo Estado, afetando a qualidade do Programa, como o Pronera/Proejapi no Piauí.

A materialização do Pronera no estado do Piauí, no contexto de implantação do Projeto de Educação de Jovens e Adultos de Assentamentos de Reforma Agrária (Proejapi), contemplou três momentos distintos, indissociáveis e concomitantes: o processo de escolarização dos jovens e adultos; as capacitações em serviço; e o acompanhamento pedagógico das salas de alfabetização. No entanto, a efetivação do Pronera/Proejapi implicou o enfrentamento das dificuldades relacionadas à precariedade estrutural dos assentamentos; ao nível de formação dos monitores; aos aspectos burocráticos de tramitação do processo; à descontinuidade na liberação das parcelas acordadas nos planos de trabalho; e ao atraso das atividades pedagógicas. Esses elementos interferiram na dinâmica de execução do Projeto e demandaram a mobilização permanente dos envolvidos para garantir as condições materiais básicas para execução da proposta.

Essa realidade revela que a educação de qualidade, também expressa nas condições estruturais tanto da escola quanto da sala de aula, elementos basilares 
para o desenvolvimento das práticas pedagógicas, é a materialização efetiva do direito à educação. Isso porque a oferta sem as condições concretas de acesso e permanência reiteram a negação desse direito, tendo como um dos indicadores desse problema o alto índice de evasão escolar.

Os esforços empreendidos no sentido de superar os desafios no processo de implantação do Programa no Piauí, coerente com a proposta do Pronera, representaram, também, processos educativos de articulação das atividades de educação formal com a realidade vivenciada nos assentamentos, condição posta para obtenção do avanço na formação crítica e reflexiva dos sujeitos, movimento imprescindível para os processos de emancipação política.

Em linhas gerais, conclui-se que a relação entre o Estado e os movimentos sociais e sindicais na implantação do Pronera/Proejapi se desdobrou em um campo de contradições que envolveu a garantia do direito à educação, as condições necessárias à permanência dos educandos e a qualidade do processo de ensino-aprendizagem. Não obstante, tais contradições, mediante a ampliação do acesso à educação, fomentaram novos contextos de luta e de escolarização, contribuindo para o processo de acumulação quantitativa e a consequente transformação qualitativa da trajetória educacional dos povos do campo.

\section{Referências}

Asseguradora do Pronera no Incra. (2019). Entrevista concedida à pesquisadora. Teresina.

Andrade, M. R., \& Di Pierro, M. C. (2004). As aprendizagens e os desafios na implementação do Programa Nacional de Educação na Reforma Agrária. In Andrade, M. R. et al (Orgs.). A educação na reforma agrária em perspectiva: uma avaliação do Programa Nacional de Educação na Reforma Agrária (pp. 37-57). São Paulo: Ação Educativa.

Azevedo, M. (2007). Política de Educação do Campo: concepções, processos e desafios. In Cabral Neto, A. et al. (Orgs.). Pontos e Contrapontos da política Educacional: uma leitura contextualizada de iniciativas governamentais (pp. 145173). Brasília, DF: Líber Livro.

Bergamasco, S. (1997). A realidade dos assentamentos rurais por detrás dos números. Estudos Avançados, 11(31), 37$49 . \quad$ https://doi.org/10.1590/S0103$\underline{40141997000300003}$

Brasil. (2003). Mapa do analfabetismo no Brasil. Brasília, DF: INEP.

Calazans, M. (1993). Para compreender a educação do estado no meio rural: traços de uma trajetória. In Therrien, J., \& Damasceno, M. (Orgs.). Educação e escola no campo (pp. 15-51). Campinas, SP: Papirus.

Caldart, R. (2010). Educação do campo: notas para uma análise de percurso. Trabalho, Educação e Saúde, 
7(1), 35-64. https://doi.org/10.1590/S198177462009000100003

Caldart, R. (2012). Pedagogia do Movimento Sem Terra. São Paulo, SP: Expressão Popular.

Coordenador do Projeto. (2019). Entrevista concedida à pesquisadora. Teresina.

Coordenador do Setor de Educação do MST no Piauí. (2019). Entrevista concedida à pesquisadora. Teresina.

Coordenadora Local. (2019). Entrevista concedida à pesquisadora. Teresina.

Coordenadora Pedagógica. (2019). Entrevista concedida à pesquisadora. Teresina.

Coutinho, A. (2009). As políticas educacionais do estado brasileiro ou de como negaram a educação escolar ao homem e a mulher do campo: um percurso histórico. EccoS Revista Científica, 11(2), 393-412.

https://doi.org/10.5585/eccos.v11i2.1931

D'Agostini, A. (2012). Educação do Campo: contradições e perspectivas. Educação, 37(3), 453-458. https://doi.org/10.5902/198464444172

Di Pierro, M. (2000). As políticas públicas de educação básica de jovens e adultos no Brasil do período 1985/1999 (Tese de Doutorado). Universidade de Campinas, São Paulo.

Di Pierro, M. (2002). O financiamento público da educação básica de jovens e adultos. In $25^{\circ}$ Reunião Anual da ANPED (pp. 1-10). Caxambu, MG.

Faleiros, V. (1986). O que é política social? São Paulo, SP: Brasiliense.

Félix, N. (2015). Programa Nacional de Educação na Reforma Agrária (Pronera): história, estrutura, funcionamento e características. In Martins, M., \& Rodrigues, S. (Orgs.). PRONERA: Experiências de Gestão de uma Política Pública (pp. 35-45). São Paulo, SP: Compacta Gráfica e Editora.

Ferraro, A. (2012). Alfabetização Rural no Brasil na Perspectiva das Relações CampoCidade e de Gênero. Educação \& Realidade, 37(3), 943-967. https://doi.org/10.1590/S217562362012000300013

Freire, P. (1968). Pedagogia do oprimido. Rio de Janeiro: Paz e Terra.

Freitas, H. (2011). Rumos da educação do campo. Aberto, Brasília, 24(85), 35-49.

Frigotto, G. (2011). Projeto societário contra-hegemônico e Educação do Campo: desafios de conteúdo, método e forma. In Munarim, A., Beltrame, S., Conte, S. F., \& Peixer, Z. (Orgs.). Educação do campo: reflexões e perspectivas (pp. 19-46). Florianópolis, SC: Insular.

Funcionária do Incra. (2019). Entrevista concedida à pesquisadora. Teresina.

Furtado, E. (2004). Estudo sobre a população rural no Brasil. In FAO/UNESCO/DGCS-Itália/CIDE-

REDUC (Org.). Educación para la población rural en Brasil, Chile, Colômbia, Honduras, México Paraguay y Perú (pp. 45-93). Santiago: FAO.

Gamboa, S. (2012). Pesquisa em educação: métodos e epistemologias. Chapecó-RS: Argos.

Gonçalves, M. (2017). "Eu era professora, era catequista, era enfermeira, eu era tudo!": a profissão docente no meio rural piauiense (1971-1989). Teresina-PI: EDUFPI. 
Hofling, E. (2001). Estado e políticas (públicas) sociais. Cad. CEDES, 21(55), 30-41. https://doi.org/10.1590/S0101$\underline{32622001000300003}$

Incra. (1998). Instituto Nacional de Colonização e Reforma Agrária. Manual de Operações do PRONERA: Programa Nacional de Educação na Reforma Agrária. Brasília, DF: MDA.

Incra. (1998). Instituto Nacional de Colonização e Reforma Agrária. Portaria $n^{\circ} 10$, de 16 de abril de 1998. Institui o Programa Nacional de Educação na Reforma Agrária.

Incra. (2001). Instituto Nacional de Colonização e Reforma Agrária. Manual de Operações do PRONERA: Programa Nacional de Educação na Reforma Agrária. Brasília, DF: MDA.

Incra. (2003). Instituto Nacional de Colonização e Reforma Agrária. Processo do convênio $n^{\circ} \quad 20.4000 / 20$ INCRA/FUNDAPE/UFPI, 2001 a 2003. Teresina, PI: Superintendência Regional do Piauí.

Incra. (2016). Instituto Nacional de Colonização e Reforma Agrária. Manual de Operações do PRONERA: Programa Nacional de Educação na Reforma Agrária. Brasília, DF: MDA.

Incra. (2018). Instituto Nacional de Colonização e Reforma Agrária. Pronera completa 20 anos de atuação educacional no campo. Recuperado de: http://www.incra.gov.br/noticias/proneracompleta-20-anos-de-atuacao-educacionalno-campo.

Marialva, M. (2011). PRONERA: política pública na educação de assentados (as) da reforma agrária (Dissertação de Mestrado). Universidade Estadual de Campinas, São Paulo.
Molina, M. (2003). A contribuição do PRONERA na construção de políticas públicas de educação do campo $e$ desenvolvimento sustentável (Tese de Doutorado). Universidade de Brasília, Distrito Federal.

Monitora Alfabetizadora/Coordenadora Local. (2019). Entrevista concedida à pesquisadora. Teresina.

Paiva, I. (2004). A dimensão educativa do fazer militante no MST. In Anais da 27a Reunião Anual da Associação Nacional de Pós-Graduação e Pesquisa em Educação (pp. 1-18). Caxambu, MG.

Paiva, R. (2013). Análise da execução orçamentária e financeira do Programa Nacional de Educação na Reforma Agrária (PRONERA) (Trabalho de Conclusão de Curso). Universidade Federal do Ceará, Ceará.

Ribeiro, M. (2013). Movimento Camponês, Trabalho e Educação: liberdade, autonomia, emancipação: princípios/fins da formação humana. São Paulo, SP: Expressão Popular.

Sampaio Jr, P. (2013). Notas críticas sobre a atualidade e os desafios da questão agrária. In Stédile, J. (Org.). A questão agrária no Brasil: debate sobre a situação e perspectiva da reforma agrária na década de 2000 (pp. 189-240). São Paulo, SP: Expressão Popular.

Sousa Sobrinho, A., Morais, L., \& Paixão, M. (2017). Alfabetização escolarização de trabalhadores do campo: parceria universidade e movimento social. Teresina, PI: EDUFPI.

Sousa, L. (2015). O Pronera na relação Incra e UESB: evidências e contradições sobre o programa (Dissertação de mestrado). Universidade Federal do Recôncavo da Bahia, Bahia. 


\begin{abstract}
Informações do Artigo / Article Information
Recebido em : 28/07/2020

Aprovado em: 12/01/2021

Publicado em: 29/03/2021

Received on July 28th, 2020

Accepted on January 12th, 2021

Published on March, 29th, 2021

Contribuições no Artigo: Os autores foram os responsáveis por todas as etapas e resultados da pesquisa, a saber: elaboração, análise e interpretação dos dados; escrita e revisão do conteúdo do manuscrito e; aprovação da versão final publicada.

Author Contributions: The author were responsible for the designing, delineating, analyzing and interpreting the data, production of the manuscript, critical revision of the content and approval of the final version published.
\end{abstract}

Conflitos de Interesse: Os autores declararam não haver nenhum conflito de interesse referente a este artigo.

Conflict of Interest: None reported.

\title{
Avaliação do artigo
}

Artigo avaliado por pares.

\section{Article Peer Review}

Double review.

Agência de Fomento

CAPES.

Funding

CAPES.

\section{Como citar este artigo / How to cite this article}

APA

Santana, J. F., Cruz, R. E., \& Gonçalves, M. C. (2021). O Projeto de Educação de Jovens e Adultos de Assentamentos de Reforma Agrária do Piauí (Proejapi) no contexto do Pronera. Rev. Bras. Educ. Camp., 6, e10135. http://dx.doi.org/10.20873/uft.rbec.e10135

ABNT

SANTANA, J. F.; CRUZ, R. E.; GONÇALVES, M. C. O Projeto de Educação de Jovens e Adultos de Assentamentos de Reforma Agrária do Piauí (Proejapi) no contexto do Pronera. Rev. Bras. Educ. Camp., Tocantinópolis, v. 6, e10135, 2021. http://dx.doi.org/10.20873/uft.rbec.e10135

\begin{tabular}{|l|l|l|l|l|l|l|} 
RBEC & Tocantinópolis/Brasil & v. 6 & e10135 & $10.20873 /$ uft.rbec.e10135 & 2021 & ISSN: 2525-4863 \\
\hline
\end{tabular}

